Гестационная гигантомастия, сопровожАающаяся некротическими изменениями Аистальных участков молочных желез. КАиническое наблюАение

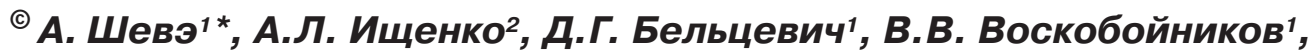 \\ В.Н. Курдюков ${ }^{1}$, Е.В. Покровская ${ }^{1}$ \\ ${ }^{1}$ Национальный медицинский исследовательский центр эндокринологии, Москва, Россия \\ ${ }^{2}$ Клиника “Артимеда", Москва, Россия
}

Редкая патология, сопровождающаяся стремительным и интенсивным разрастанием ткани молочной железы, получила название “гигантомастия". Гестационная гигантомастия возникает непосредственно в период беременности и является жизнеугрожающим состоянием как для матери, так и плода, при этом риск потери плода осложняет выбор тактики лечения. В статье представлен клинический случай пациентки, обратившейся с жалобами на прогрессирующее увеличение молочных желез, дебют заболевания которой пришелся на 5-ю неделю гестации и впоследствии осложнился трофическими изменениями дистальных тканей молочных желез. Трудность выбора метода лечения в подобных случаях, с одной стороны, заключается в небезопасности выжидательной тактики в связи с высоким риском развития септических осложнений, а с другой стороны, обусловлена угрозой потери плода в случае оперативного лечения на ранних сроках беременности. После адекватной оценки состояния матери принято решение о выжидательной тактике до полного формирования плацентарного барьера. На 19-й неделе беременности проведена тотальная двусторонняя мастэктомия с благоприятным исходом для пациентки и ее ребенка. Данный случай подчеркивает важность индивидуального, междисциплинарного подхода к выбору тактики ведения пациенток с данной патологией.

Ключевые слова: гигантомастия, макромастия, гестационная, беременность, мастэктомия, клинический случай.

\title{
Gestational gigantomastia accompained by distal breast tissue necrosis. A case report
}

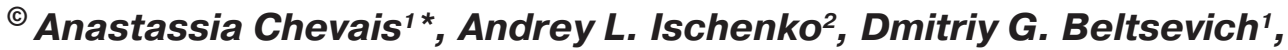 \\ Valeriy V. Voskoboynikov', Valeriy N. Kurdyukov', Elena V. Pokrovskaya'
}

${ }^{1}$ Endocrinology Research Centre, Moscow, Russia

${ }^{2}$ Medical center "Artimeda", Moscow, Russia

\begin{abstract}
Rare condition characterized by an intensive and excessive breast enlargement is known as gigantomastia. Gestational gigantomastia manifests during pregnancy and could represent a life-threatening condition for both the mother and the fetus, therefore the risk of spontaneous abortion complicates the choice of treatment approach. We present a clinical case of a patient requesting medical assistance with a progressive breast growth. The onset occurred on the 5th week of gestation and, subsequently, was aggravated by distal tissue necrosis. The ambiguity of treatment approach in such situation is based on, on the one hand, the insecurity of watch-and-wait approach due to the high risk of septic complications and, on the other hand, the increasing danger of fetal loss in the case of surgical treatment during the first trimester of pregnancy. After an adequate assessment of mother's health state, a decision was made towards the wait-andsee tactic until the complete formation of the placental barrier. A total bilateral mastectomy was performed at the 19th week of pregnancy, with a favorable outcome for the patient and her child. This case emphasizes the significance of an individual, interdisciplinary approach to the choice of management for patients with this pathology.
\end{abstract}

Keywords: gigantomastia, macromastia, gestational, pregnancy, mastectomy, case report.

() ОО Российская ассоциация эндокринологов, 2019

(c) Russian association of endocrinologists, 2019
The article can be used under the CC BY-NC-ND 4.0 license. 141 Статья может быть использована на условиях международной лицензии CC BY-NC-ND 4.0. 


\section{Актуальность}

Гигантомастия (ГМ), также известная как макромастия, - редкое состояние, характеризующееся патологическим, интенсивным, одно- или двусторонним разрастанием ткани молочной железы (МЖ), возникающее, как правило, вследствие резкого изменения гормонального фона у женщины. Некоторые авторы предлагают определять гигантомастию как избыток ткани молочной железы, который составляет $3 \%$ и более от общей массы тела пациентки [1]. Вес одной удаленной железы сильно варьирует (1,35-27,5 кг), усредненный показатель составляет около 6,7 кг [2]. Часть авторов разделяют понятия гигантомастии и макромастии, принципиальным отличием между которыми считают не столько наличие больших по весу и размеру желез, иногда генетически обусловленное (макромастия), а неуправляемое относительно быстрое патологическое разрастание ткани МЖ, которое может приводить к нарушению трофики тканей МЖ (ГМ).

Выделяют несколько вариантов ГМ:

- гестационная, или ГМ беременных, возникающая непосредственно во время беременности;

- пубертатная, которая в свою очередь дебютирует в период полового созревания;

- медикаментозно-индуцированная, обусловленная приемом таких препаратов, как Д-пеницилламин, неотетазон, циклоспорин, буцилламин;

- идиопатическая ГМ [3, 4].

По вариантам течения заболевания выделяют следующие формы:

- агрессивная, характеризующаяся интенсивным нарастанием клинических проявлений в короткий срок до нескольких месяцев;

- вялотекущая, сопровождающаяся медленным ростом МЖ на протяжении нескольких лет;

- абортивная, при которой отмечается спонтанная стабилизация роста [5].

Этиология и патогенез данного заболевания остаются неизвестными. Ввиду того что большинство случаев ГМ приходятся на пубертатный период и беременность, одна из возможных причин - гиперэстрогения или гиперпролактинемия [6, 7]. Однако у части пациенток ГМ развилась на фоне нормального уровня гормонов $[8,9]$. Ряд авторов указывают на возможность гиперчувствительности рецепторов в МЖ. Отдельные гистологические исследования показали увеличение количества эстрогеновых рецепторов в железистой ткани, а также гиперчувствительность рецепторов как к эстрогену, так и к прогестерону у пациенток с ГМ [3, 6-8]. Гиперчувствительность тканей к пролактину в большей степени характерна для гестационной ГМ [6-8], в то время как ювенильная гигантомастия, как полагают, обусловлена повышенной реактивностью ткани МЖ к воздействию других гормонов [3, 7]. Несколько авторов предложили возможную аутоиммунную гипотезу этиологии ГМ, так как достаточно часто описываются случаи ее сочетания с аутоиммунными заболеваниями, такими как миастения, системная красная волчанка, аутоиммунный тиреоидит, псориаз, ревматоидный артрит, недифференцированные заболевания соединительной ткани [7, 10-15]. В эту концепцию также вписывается ГМ, индуцированная приемом Д-пеницилламина или буцилламина - препаратов, которые известны провокацией аутоиммунных реакций [13]. Вероятнее всего, этиология данного заболевания является многофакторной и требует дальнейшего, более детального изучения.

Ввиду яркости клинических проявлений для постановки диагноза ГМ достаточно проведения физикального обследования. Симптомы связаны с увеличением размера и веса ткани МЖ и включают в себя боль в плечах, спине, шее, груди, ограничение в движении за счет смещения центра тяжести вперед и, как следствие, искривление позвоночника. Кожные изменения МЖ включают атрофию, как гиперемию, так и гиперпигментацию, резкое расширение ареолы. При неуправляемом увеличении МЖ присоединяются сосудистые изменения - выраженный венозный застой, тромбоз подкожных вен МЖ и грудной стенки, который вызывает необратимые трофические изменения тканей МЖ, при этом в первую очередь страдают дистальные участки железы (сосково-ареолярный комплекс), которые подвергаются изъязвлению и некрозу. При запущенных 
формах присоединяется интеркуррентная инфекция и интоксикационный синдром: слабость, одышка, токсическая анемия $[14,16]$. Зачастую пациентка испытывает не только физический дискомфорт, но и психологический, что приводит к психосоматическим нарушениям: фрустрации, отчужденности и депрессии $[3,14,16]$.

Существует несколько вариантов лечения этого состояния - медикаментозный, оперативный или комбинированный методы. Лекарственные препараты включают бромокриптин, каберголин, медроксипрогестерон, тамоксифен и даназол [4, 7, 17-19]. Хирургическое лечение подразумевает тотальную мастэктомию, а в некоторых случаях редукционную маммопластику. Однако большинство авторов отмечают, что пациентки, перенесшие редукционную маммопластику вместо тотальной мастэктомии, находятся в группе риска рецидива, особенно при последующей беременности, при этом риск рецидива крайне высок [20-22]. Поэтому на данный момент, по мнению большинства авторов, методом выбора является тотальная мастэктомия.

Беременность осложняет выбор варианта лечения, так как выжидательная тактика не всегда представляется возможной, медикаментозная терапия оказывается неэффективной и небезопасной, а оперативное вмешательство может привести к потере плода.

\section{Описание клинического случая}

Пациентка Ф., 43 года, в январе 2019 г. поступила в ФГБУ "НМИЦ эндокринологии" с жалобами на активно прогрессирующее увеличение молочных желез, боли в грудном и поясничном отделах позвоночника, ограничение физической активности (появление одышки при ходьбе).

Из анамнеза известно, что 2 года назад в рамках предимплантационной подготовки к экстракорпоральному оплодотворению (ЭКО) пациентка получала терапию эстрадиолом (Дивигель). В первые два месяца приема препарата отмечалось выраженное увеличение и уплотнение груди, после чего препарат был отменен. Во избежание дальнейшего прогрессирования гиперплазии молочных желез настоятельно рекомендовалась тотальная мастэктомия. Зимой 2017 г. проведена редукционная маммопластика
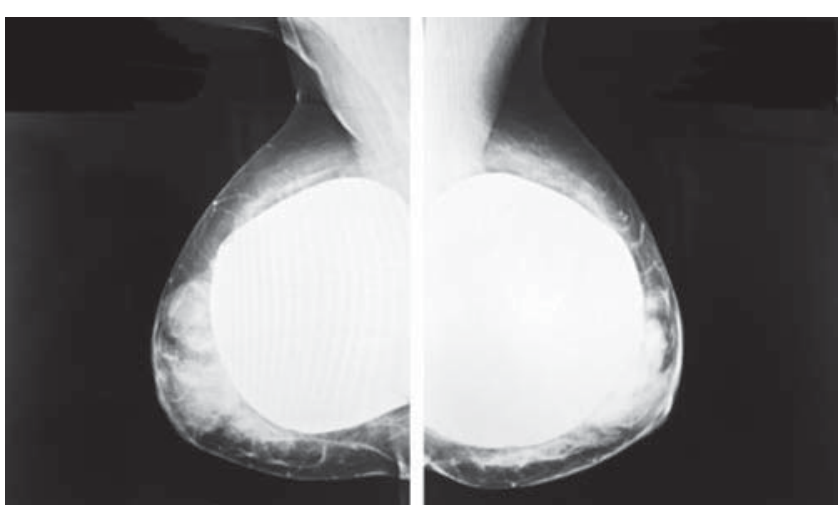

Рис. 1. Маммография 2017 г. после субтотальной редукционной пластики с протезированием.

с оставлением минимального количества железистой ткани, мастопексия с переносом сосковоареолярного комплекса, имплантация силиконовых протезов (500 мл). Данные послеоперационной маммографии МЖ приведены на рис. 1. В сентябре 2018 г. в ходе протокола ЭКО была выполнена подсадка эмбриона в полость матки. Начиная с 5-й недели беременности зафиксировано стремительное увеличение молочных желез, покраснение кожи в параареолярной зоне. В ноябре при обращении к хирургу размер груди увеличился с 3-го до 20-го. Данные гормонального исследования крови от 2 декабря 2018 г., на момент гестации 12 нед, приведены в таблице.

C середины декабря пациентка отметила резкое ухудшение состояния: появились жалобы на боль, повышение температуры тела, изъязвление нижних отделов груди. Медикаментозное лечение тамоксифеном, даназолом, медроксипрогестероном не рассматривалось ввиду небезопасности данных препаратов при беременности, а учитывая нормальные показатели пролактина, терапия каберголином или бромокриптином у данной пациентки представлялась нерациональной. В свою очередь хирургическое лечение в первом триместре сочетано с высоким риском преждевременного прерывания бере-

Таблица. Гормональный анализ крови, 12-я неделя гестации

\begin{tabular}{l|c|c}
\hline \multicolumn{1}{c|}{ Параметр } & Результат & $\begin{array}{c}\text { Норма } \\
\text { при сроке 12 нед }\end{array}$ \\
\hline Пролактин & $361 \mathrm{mME} / л$ & $189-4011 \mathrm{MME} / л$ \\
Эстрадиол & 9880 пмоль/л & $2280-3120$ пмоль/л \\
Прогестерон & 75,39 нмоль/л & $92,1-110$ нмоль/л \\
\hline
\end{tabular}




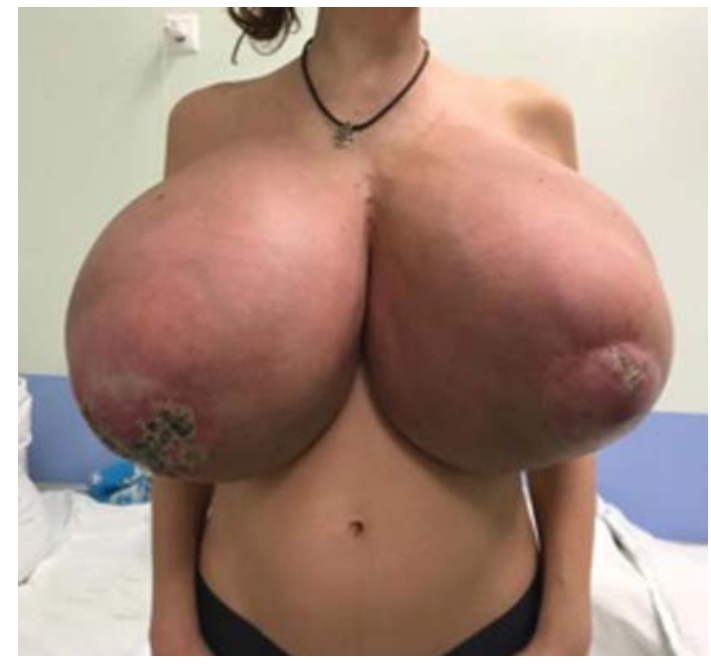

Рис. 2. Гигантомастия на 18-й неделе беременности. Вид в анфас.

менности. В связи с желанной беременностью было принято решение о выжидательной тактике до полного формирования плаценты. На гестационном сроке 18 нед, после контрольного УЗИ на предмет сформированности плацентарного и плодового барьера, пациентка госпитализирована для планового оперативного лечения.

\section{Данные физикального обследования}

Состояние больной средней тяжести. Самостоятельное передвижение затруднено вследствие большой массы МЖ (около 16 кг). Наблюдается одышка в покое. Вынужденное положение - лежа. Температура тела - 37,2 ${ }^{\circ} \mathrm{C}$. Индекс массы тела - 26,6 кг/м². При осмотре МЖ гигантских размеров (рис. 2, 3). Правая незначи-

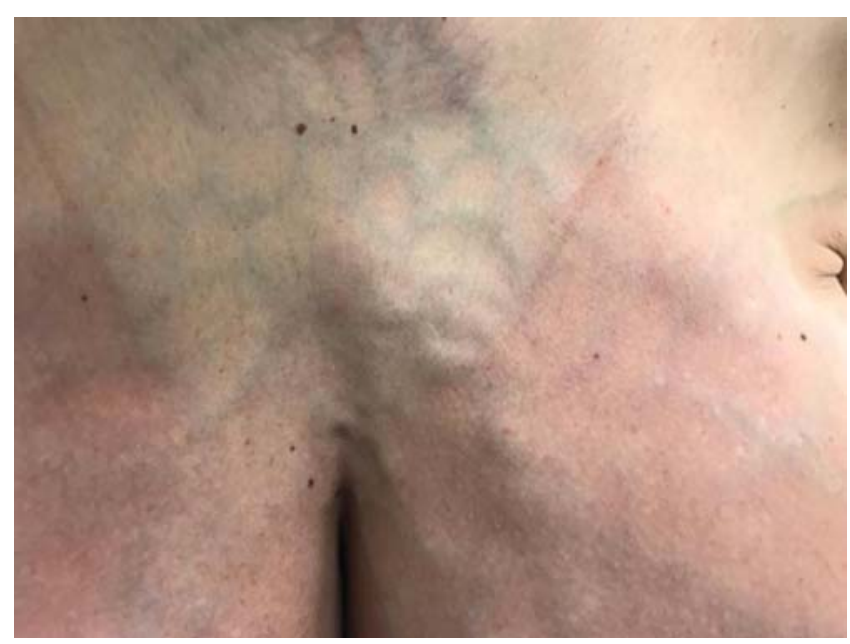

Рис. 4. Расширение поверхностных вен с признаками тромбоза.

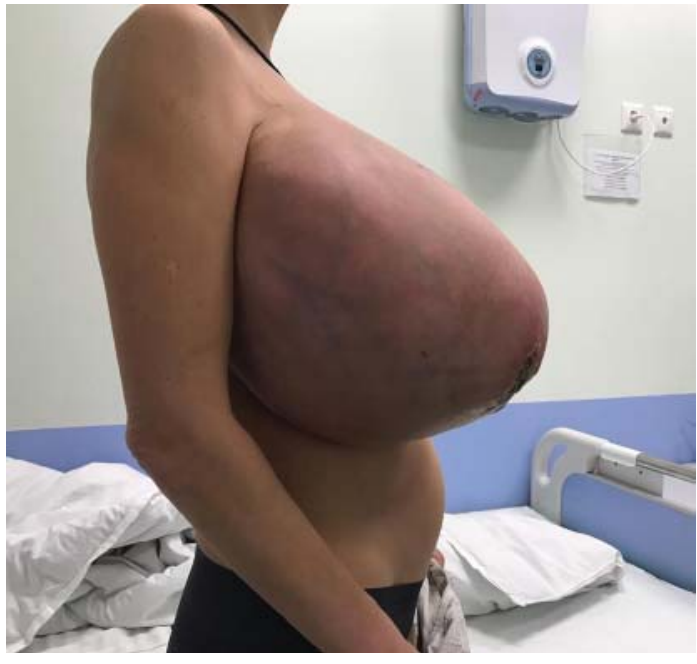

Рис. 3. Гигантомастия на 18-й неделе беременности. Вид в профиль.

тельно больше, чем левая. Кожа гиперемирована, напряженная, горячая на ощупь. На передней поверхности грудной клетки отмечается расширение поверхностных вен с признаками тромбоза (рис. 4). При пальпации МЖ железистой структуры с узловыми образованиями 3-5 см в диаметре, болезненные, с явлениями лимфостаза и трофическими нарушениями в нижних отделах. В дистальной части правой и левой МЖ (зона ареол) участок некротизированной ткани, с плотными краями и серозным отделяемым.

\section{Данные лабораторных исследований при поступлении \\ - Гемоглобин (Hb) - 116 г/л (117-155 г/л) \\ - СОЭ - 33 мм/4 (0-20 мм/4) \\ - D-димер - 2534,0 нг/мл (216,0-1211 нг/мл) \\ Лечение}

В январе 2019 г. на сроке 19 нед проведена двусторонняя тотальная мастэктомия с удалением протезов и сосково-ареолярных комплексов.

Из особенностей операции: в подкожно-жировой клетчатке, ближе к некротизированным ареолам выраженный стекловидный отек, неспадающиеся расширенные вены, в связи с чем интраоперационно кровопотеря составила 1,5 л. Непосредственно после операции на фоне адекватной гемотрансфузии $\mathrm{Hb}-88$ г/л.

С выраженными техническими сложностями выполнено подкожное удаление молочных желез с одновременным извлечением имплантов. Вес удаленной левой железы - 6400 г, правой - 6900 г. По данным интраоперационного трансабдоминального УЗИ ЧСС плода - 110 уд/мин. 
В связи со значительной кровопотерей и развитием токсической анемии (снижение уровня $\mathrm{Hb}$ до 65 г/л) в раннем послеоперационном периоде проводилась трансфузия компонентов крови и плазмы, кровезаменителей, а также профилактика стрессовых язв ингибиторами протонной помпы. Необходимо отметить, что отмечалась определенная резистентность показателей красной крови в ответ на гемотрансфузию, при отсутствии других признаков кровопотери, что свидетельствует в пользу токсического характера анемии, обусловленной применением в ходе операции электрокоагуляционной аппаратуры и, как следствие, обширной ожоговой раной. На вторые сутки после операции отмечалась нормализация Д-димера (384 нг/ мл). Дренажи сняты на пятые сутки. Выписана из стационара в удовлетворительном состоянии на седьмые сутки, показатель Нb при выписке 90 г/л. Весь послеоперационный период пациентка и плод находились под ежедневным мониторингом акушера-гинеколога, отклонения показателей плода, плацентарного барьера не отмечено. Выполнение второго (косметического) этапа операции планируется после родоразрешения.

По данным гистологического исследовании: ткань молочных желез с наличием участков резко увеличенных железистых долек, аденоза, протоковой гиперплазии, а также гиперплазии рыхлой миксоматозной соединительной ткани. В строме очаги отека, полнокровные сосуды.

\section{ЗакАючение}

Данный клинический случай демонстрирует сложность определения метода лечения при осложненной трофическими изменениями гестационной ГМ.

В первую очередь при необходимости выжидательной тактики для оптимального времени оперативного вмешательства необходима правильная оценка гормонального профиля для решения вопроса о возможной консервативной терапии. С учетом изолированной гиперэстрогении консервативное лечение в нашем наблюдении было нецелесообразно. До оперативного лечения необходимо рекомендовать пациенткам палатный режим, адекватную антитромботическую терапию и проводить направленную подготовку в отношении анемии и предполагаемой кровопотери с целью снижения риска гипоксии плода.

Наличие беременности требует не только выбора оптимального времени оперативного вмешательства, но и тщательного послеоперационного мониторинга состояния плацентарного барьера и плода. В нашем случае отрицательного влияния данного метода лечения на плод не было выявлено: по данным контрольных УЗИ на 20-й, 23-й неделях ребенок развивался согласно сроку гестации.

Возможность и целесообразность выжидательной тактики у пациенток с гестационной ГМ, помимо показателей плода, требует и адекватной оценки состояния матери, в первую очередь интоксикационного, тромботического и септического компонентов.

Анамнез заболевания - наличие у пациентки гиперчувствительности ткани МЖ к препаратам эстрогенового ряда до возникновения беременности - является лишь подтверждением того, что органосохраняющая резекция МЖ при ГМ является нерациональным объемом операции, таким образом, методом выбора при ГМ является тотальная мастэктомия. В ФГБУ “НМИЦ эндокринологии" за последние 23 года прооперировано 5 пациенток с ГМ, из них у троих (включая описываемый клинический случай) предварительно была выполнена субтотальная резекция $\mathrm{M}$ Ж.

У всех прооперированных нами пациенток также отмечалась токсическая послеоперационная анемия, не соответствующая по лабораторным показателям объему кровопотери и ригидная в течение нескольких дней к переливанию эритроцитарной массы. С нашей точки зрения, это требует превентивного планирования ведения больных в послеоперационном периоде.

Ведение больных с ГМ требует оценки возможных проявлений сочетанных аутоиммунных заболеваний со стороны различных систем органов: функции почек, щитовидной железы, наличия мышечных резервов. У двух наших пациенток была выявлена генерализованная форма миастении: в первом случае диагноз был известен до операции, во вто- 
ром - манифестация миастении произошла на фоне интраоперационного введения миорелаксантов.

\section{Аополнительная информация}

Согласие пациента. Пациентка добровольно подписала информированное согласие на публикацию персональной медицинской информации.

Конфликт интересов. Авторы декларируют отсутствие явных и потенциальных конфликтов интересов, связанных с публикацией настоящей статьи.

\section{Список ^итературы (References)}

1. Dafydd H, Roehl KR, Phillips LG, et al. Redefining gigantomastia. J Plast Reconstr Aesthet Surg. 2011;64(2):160-163. doi: https://doi.org/10.1016/j.bjps.2010.04.043.

2. Mojallal A, Moutran M, Martin E, Braye F. Gigantomastia a classification and review of the literature. J Plast Reconstr Aesthet Surg. 2009;62(2):262-263.

doi: https://doi.org/10.1016/j.bjps.2008.07.014.

3. Bland KI, Copeland EM, Klimberg VS, Gradishar WJ, editors. The breast: comprehensive management of benign and malignant diseases. 5th ed. Elsevier Inc; 2018. pp. 92-178. doi: https://doi.org/10.1016/C2014-0-01946-6.

4. Gayon-Vera E. Danazol as an effective treatment in a premenarchal girl with juvenile breast hypertrophy. Research. 2014;1:755. doi: https://doi.org/10.13070/rs.en.1.755.

5. Тютюнник В.Л., Шифман Е.М., Параконная А.А., Балушкина А.А. Макромастия, манифестировавшая при беременности. Клинические наблюдения с двусторонней мастэктомией и благоприятным исходом // Акушерство и гинекология. - 2012. - №6. - С. 81-84. [Tyutyunnik VL, Shifman EM, Parakonnaya AA, Balushkina AA. Macromastia of pregnancy: clinical cases of bilateral mastectomy and a good outcome. Akush Ginekol (Mosk). 2012;(6):81-84. (In Russ.)]

6. Shimatsu A, Hattori N. Macroprolactinemia: diagnostic, clinical, and pathogenic significance. Clin Dev Immunol. 2012; 2012:167132. doi: https://doi.org/10.1155/2012/167132.

7. Dancey A, Khan M, Dawson J, Peart F. Gigantomastia a classification and review of the literature. J Plast Reconstr Aesthet Surg. 2008;61(5):493-502. doi: https://doi.org/10.1016/j.bjps.2007.10.041.

8. Swelstad MR, Swelstad BB, Rao VK, Gutowski KA. Management of gestational gigantomastia. Plast Reconstr Surg. 2006;118(4):840-848. doi: https://doi.org/10.1097/01.prs.0000232364.40958.47.

9. Antevski BM, Smilevski DA, Stojovski MZ, et al. Extreme gigantomastia in pregnancy: case report and review of literature. Arch Gynecol Obstet. 2007;275(2):149-153. doi: https://doi.org/10.1007/s00404-006-0190-7.

10. Le EN, McGrit LY, Abuav R. Gigantomastia and autoimmunity: a case report. Lupus. 2009;18(11):1015-1018. doi: https://doi.org/10.1177/0961203309105362.
11. Govrin-Yehudain J, Kogan L, Cohen HI, Falik-Zaccai TC. Familial juvenile hypertrophy of the breast. J Adolesc Health. 2004;35(2):151-155. doi: https://doi.org/10.1016/j.jadohealth.2003.09.017.

12. Lanzon A, Navarra S. Gigantomastia in a patient with systemic lupus erythematosus successfully treated by reduction mammoplasty. Lupus. 2009;18(14):1309-1312. doi: https://doi.org/10.1177/0961203309106690.

13. Щербакова Н.И., Хрущева Н.А., Антонова К.В., и др. Сочетание миастении и гигантомастии: тесное переплетение аутоиммунных гормональных и паранеопластических факторов // Неврологический журнал. - 2017. T.22. - №1. - C. 25-32. [Shcherbakova NI, Khrushcheva NA, Antonova KV, et al. The association of autoimmune, hormonal and paraneoplastic factors in myasthenia with gigantomastia. Nevrologicheskii zhurnal/Journal of neurology. 2017;22(1): 25-32. (In Russ.)] doi: https://doi.org/10.18821/1560-95452017-22-1-25-32.

14. Воскобойников В.В., Ищенко А.Л., Фирсов А.В., и др. Сочетание макромастии и миастении. Клиническое наблюдение // Эндокринная хирургия. - 2014. - Т.8. - №3. C. 35-38. [Voskoboinikov VV, Ishchenko AL, Firsov AV, et al. The combination of macromastia and myasthenia gravis. Clinical observation. Endocrine surgery. 2014;8(3):35-38. (In Russ.)] doi: https://doi.org/10.14341/serg2014335-38.

15. Zingaretti N, De Biasio F, Riccio $M$, et al. A case of gestational gigantomastia in a 37-years-old woman associated with elevated ANA: a casual linkage? Pan Afr Med J. 2017; 27:167. doi: https://doi.org/10.11604/pamj.2017.27.167.11281.

16. Rezai S, Nakagawa JT, Tedesco J, et al. Gestational gigantomastia complicating pregnancy: a case report and review of the literature. Case Rep Obstet Gynecol. 2015;2015:892369. doi: https://doi.org/10.1155/2015/892369.

17. Dellal FD, Ozdemir D, Aydin C, et al. Gigantomastia and macroprolactinemia responding to cabergoline treatment: a case report and minireview of the literature. Case Rep Endocrinol. 2016;2016:3576024. doi: https://doi.org/10.1155/2016/3576024.

18. Demir K, Unuvar T, Eren S, et al. Tamoxifen as first-line treatment in a premenarchal girl with juvenile breast hypertrophy. J Pediatr Adolesc Gynecol. 2010;23(5):e133-136. doi: https://doi.org/10.1016/j.jpag.2009.11.003.

19. Sridhar GR, Sinha MJ. Macromastia in adolescent girls. Indian Pediatr. 1995;32(4):496-499.

20. Chargui R, Houimli S, Damak T, et al. [Relapse of gigantomastia after mammoplasty. Report of a case and literature review. (In French).] Ann Chir. 2005;130(3):181-185. doi: https://doi.org/10.1016/j.anchir.2004.12.007.

21. Benna $M$, Naser RB, Fertani $Y$, et al. Extreme idiopathic gigantomastia. Int J Res Med Sci. 2018;6(5):1808-1811. doi: https://doi.org/10.18203/2320-6012.ijrms20181782.

22. Boufettal $H$, Khalkane $L$, Dlia $H$, et al. [Bilateral gestational macromastia: about one case. (In French).] Imagerie de la femme. 2013;23(1):32-35. doi: https://doi.org/10.1016/j.femme.2013.02.003. 


\section{Информация об авторах (Authors info)}

*Шевэ Анастасия, клинический ординатор [Anastassia Chevais, medical resident], адрес: Россия, 117036, Москва, ул. Дм. Ульянова, д. 11 [address: 11 Dmitry Ulyanova street, 117036 Moscow, Russia] Тел.: +7-962-993-27-63; ORCID: https://orcid.org/0000-0001-5592-4794; eLibrary SPIN: 2459-0540; e-mail: anastassia93@gmail.com

Ищенко Андрей Леонидович, к.M.н. [Andrey L. Ischenko, MD, PhD]; ORCID: https://orcid.org/0000-0002-8349-2666; eLibrary SPIN: 5274-4260; e-mail: plastic.sur@gmail.com

Бельцевич Дмитрий Германович, д.м.н., профессор [Dmitriy G. Beltsevich, MD, PhD, Professor]; ORCID: https://orcid.org/0000-0001-7098-4584; eLibrary SPIN: 4475-6327; e-mail: belts67@gmail.com

Воскобойников Валерий Витальевич, к.м.н. [Valeriy V. Voskoboynikov, MD, PhD]; ORCID: https://orcid.org/0000-0003-3911-6636; eLibrary SPIN: 8438-8887; e-mail: vall_nat@rambler.ru Курдюков Валерий Николаевич, врач-анестезиолог [Valeriy N. Kurdyukov MD]; ORCID: https://orcid.org/0000-0002-4917-5683; eLibrary SPIN: 9084-3591; e-mail: vnk19doc75@gmail.com Покровская Елена Владиславовна, научный сотрудник [Elena V. Pokrovskaya, MD]; ORCID: https://orcid.org/0000-0001-5268-430X; eLibrary SPIN: 8769-5010; e-mail: pokrovskaya.93@mail.ru

\section{Как цитировать}

Шевэ А., Ищенко А.Л., Бельцевич Д.Г., Воскобойников В.В., Курдюков В.Н., Покровская Е.В. Гестационная гигантомастия, сопровождающаяся некротическими изменениями дистальных участков молочных желез. Клиническое наблюдение // Эндокринная хирургия. - 2019. - Т. 13. - №3. - С. 141-147. doi: https://doi.org/10.14341/serg10306

\section{To cite this article}

Chevais A, Ischenko AL, Beltsevich DG, Voskoboynikov VV, Kurdyukov VN, Pokrovskaya EV. Gestational gigantomastia accompained by distal breast tissue necrosis. A case report. Endocrine surgery. 2019;13(3): 141-147. doi: https://doi.org/10.14341/serg10306

Рукопись получена: 01.10.2019.

Received: 01.10.2019.
Рукопись одобрена: 23.12.2019. Accepted: 23.12.2019.
Опубликована online: 25.12.2019.

Published online: 25.12.2019. 